\title{
STUDIES FOR THE CONSERVATION AND VALORISATION OF THE ARCHAEOLOGICAL ROCK HERITAGE OF CALASCIBETTA IN SICILY, ITALY
}

\author{
A. Versaci ${ }^{1}$, A. Lo Cascio ${ }^{1}$, L.R. Fauzìa ${ }^{1}$, A. Cardaci ${ }^{2, *}$ \\ ${ }^{1}$ Faculty of Engineering and Architecture, University of Enna 'Kore', Italy - antonella.versaci@unikore.it, \\ alexa.locascio@virgilio.it, luca.fauzia@unikore.it \\ ${ }^{2}$ School of Engineering, University of Bergamo, Italy - alessio.cardaci@unibg.it
}

Commission II - WG II/8

KEY WORDS: Rock villages, Conservation, 3D survey, Documentation, Valorisation

\begin{abstract}
:
The rock settlement of Vallone Canalotto, which stands in the valleys surrounding the town of Calascibetta - about three kilometres north from Enna, Sicily, Italy - testify to a widespread population of the area from prehistoric times up to the Middle Ages, probably linked to the agricultural and pastoral exploitation of its fertile land. This valuable heritage, dug into very soft limestone banks, is now threatened by significant erosion and disruption phenomena, which, in the absence of adequate safeguarding and maintenance actions, will lead to a progressive loss of material and the consequent collapse of some portions, making the documentable traces more and more paltry. The archaeological complex demonstrates the continuity of the funerary use from the remotest ages to the early Christian era, as testified by the excavation of rupestrian columbaria. In the early medieval period, small rural communities used the hypogeal structures for residential and religious purposes. In the present work, integrated procedures have been put in place for the 3D documentation of these artefacts, whose effectiveness has already been tested by the same team in other Sicilian rock sites. The research aims at the knowledge and cataloguing of places, which are important for the Island's history but to date only marginally explored. It intends to stimulate and plan adequate conservation and enhancement activities. To improve the attendance of the sites, design proposals have been developed to guarantee greater accessibility to the archaeological areas and their understanding by visitors.
\end{abstract}

\section{THE ARCHAEOLOGICAL BASIN OF THE CITY OF CALASCIBETTA}

Calascibetta is a small town located in the middle of Sicily ${ }^{1}$, Italy. Its strategic situation at the crossroads of the major trade and communication routes has made it a valuable archaeological open-air museum. Necropolis, cave dwellings and hypogea - in which archaeological findings such as jewellery, fragments of ancient tiles and ceramics have been found - testify a constant and widespread human frequentation since the remotest ages. In the area, there are several settlements, mainly carved into the rock. They originate from a morphology of the ground consisting of large cliffs and high escarpments, which both allowed their construction and defence. The presence of numerous springs, the soil rich in minerals and the hydrogeological structure which favoured the rapid achievement of the main neighbouring rivers - determined a constant attendance over the time and the emergence of numerous activities related to agriculture and pastoralism. Therefore, the whole system is a single vast archaeological basin - like the more well-known areas of Pantalica in the Hyblaean Mountains or the Addaura caves in Palermo - but unfortunately still little investigated today (Figure 1).

The richness of the basin is confirmed by the hypogea of the prehistoric necropolises placed in the Valle Coniglio and Caldarella districts, as well as by the more famous "cliff frayed with caves" mentioned by Johann Wolfgang von Goethe in his Italian Journey. A system of over three hundred grotticella

* Corresponding author

1 The name Calatxibet derives from the Arabic: the prefix 'Càlat' means natural fortress, followed by the name of the mount, Xibet. tombs in Realmese, dating back to the period between the 9th and 8th centuries B.C. and, on the top of the hill, the remains of a Sicilian village attested by the discovery of small objects, jewellery and coins. Moreover, by the tombs in Malpasso - very relevant for the particularity of their 'cluster' structure, a rare example in Sicily, but widely spread in Malta and Sardinia and, nearby, by the remnants of some houses dating back to the second millennium B.C. (Cardaci et al., 2015).

The city of Calascibetta itself is characterized by caves excavated in ancient times. Now incorporated into the urban fabric, they were used in medieval times as homes and later, until the beginning of the last century, like warehouses and stables.

Part of the same basin and the focus of this essay is the socalled Byzantine village in Vallone Canalotto, one of the most extensive sites in the area. Here it is still possible to make a chronological reading of the place and an interpretation of the use of the hypogea up to the recent past. The village lies in the lower part of a deep valley characterized by a sandstone rock where, over the centuries, numerous environments have been excavated to fulfil multiple functions: funerary, housing, religious and finally agricultural. In the Copper Age, the site became a necropolis as the different tombs recovered highlight. The presence in some caves of small niches along the wall, probably columbaria used to store urns, indicates the ensuing exploitation of the place even during the Roman period.

However, the importance of the village dates back to the Byzantine period when rural structures were used both as homes and as sacred places related to the nascent Christian cult. Its peculiarity is due to the high number of rooms for worship compared to those used for other purposes. There are at least 
four ancient rock churches, characterized by crosses and religious symbols engraved in the rock and built during the first phase of the Christianization of Sicily. Two of them are very particular because they have a Basilica layout with a single nave and annexed service rooms.

The presence of qanāt - an ancient type of water-supply system $^{2}$ - testifies to the growth of the site during the Arab dominations of the 9th and 10th centuries (Amata, 2016). In the 11th century, a monastic community stably occupied the site. It was then adapted to production purposes in support of the community requirements. New semi-hypogean structures for viticulture were built, millstones obtained in the rocky plain and characterized by decanting tanks, small buildings for the conservation of wheat and mills for the processing of olives, mills with tanks and adduction channels marked by regular cuts along the walls. A complex system that starts to exploit the entire valley, evidenced by connecting paths and numerous retaining walls for agricultural terracing, which are still clearly visible and were in use until the beginning of the 20th century (Figure 2).

Despite its undoubted value, the site as, in general, Central Sicily has aroused little interest in the past by archaeologists, perhaps because of its isolated position far from the coast. Systematic research is very recent but very poor. The same Archaeological Map of the Sicilian Region, until the mid-50s of the last century, excluded many sites including the Byzantine village in Calascibetta. To date, many doubts persist as regards the settlement dynamics of the various populations that over the centuries have inhabited this place, because of the few documentary sources, the alienation or loss of the remains and the lack of documented excavations, conducted by the stratigraphic technique.

It was, then, necessary to start a new investigation of the rocky site - starting from a critically planned three-dimensional survey and to make appropriate analyses on its typological, chronological and functional characteristics. The aim is to understand the reasons and processes that have influenced its history, together with that of the entire archaeological system.

\section{THE 3D SURVEY FOR THE METRIC AND MORPHOLOGICAL UNDERSTANDING}

In recent years, an extended notion of 'survey' has been reached, especially with regards to the safeguarding of the archaeological and architectural heritage: the field in which it is the most used. Consequently, the survey cannot be limited to the act of measuring, i.e. the simple acquisition of metric information aimed at the reconstruction of a virtual model of reality (Cigola, 2001). It is also and above all a tool to understand the reality based on the knowledge of cultural goods, which includes historical, material and conservation status information (Dezzi Bardeschi, 2017).

This assumption is of fundamental importance in the case of the Byzantine Village because it is composed by architectures mainly 'carved' and not 'erected', which result from man's need to create spaces and adapt them over the centuries according to the changing of use.

2 A qanāt taps underground mountain water sources trapped in and beneath the upper reaches of alluvial fans and channels the water downhill through a series of gently sloping tunnels, often several kilometres long, to the places where it is needed for irrigation and domestic use.

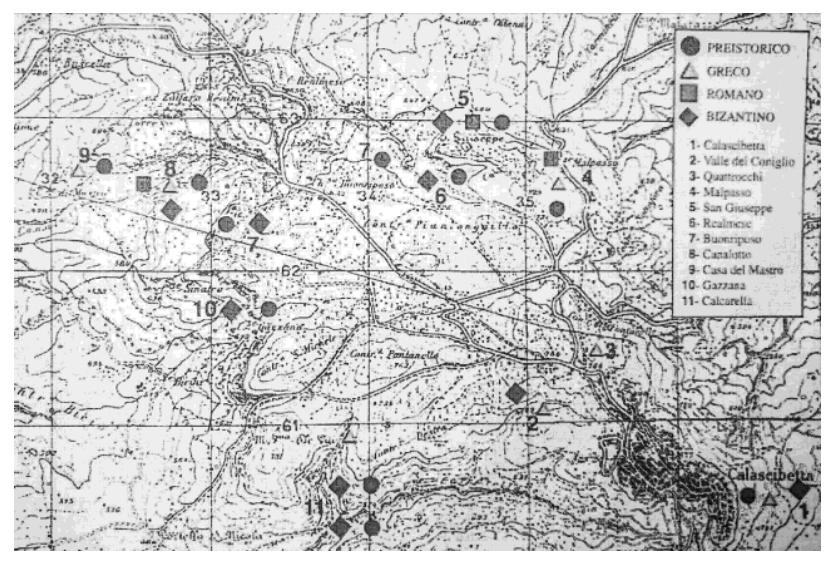

Figure 1. Archaeological sites in the territory of Calascibetta.

The 3D model - irreplaceable today - does not represent the aim of knowledge, but the 'virtual object' on which to set the reflections, comparisons, and evaluations necessary for the conservation project. Historical and archaeological research, combined with an investigation into the physical, chemical and mechanical characteristics of the properties and alterations underway, is the action that has so far been missing in Vallone Canalotto's site. They are a valid and indispensable tool for finding data on the intrinsic qualities of the place, to establish maintenance cycles and any future restorations, based on correct and sustainable methodological processes.

However, the acquisition of three-dimensional metric data and their subsequent modelling is very useful, also for the careful cataloguing and their possible future transformation into a document set in an HBIM environment, shareable, interoperable and accessible by different operators and professionals, equally interested in the asset's safeguarding.

The experience carried out in Calascibetta has therefore been motivated by the absence of significant drawings of the excavated caves. Their documentation - when existing consisted of simple photographic images and incomplete and inaccurate planimetric sketches. An exhaustive morphological study of the hypogean spaces aimed at recognizing construction singularities, carried out according to rigorous and accurate measurement procedures, was completely absent. This was largely due to the difficulties inherent in undertaking these activities in such complex and articulated places (Figure 3).

Artificial cavities are tangible signs of actions of our ancestors: a heritage that has singularities in that each cavity obtained by the act of 'removing' is an original and unrepeatable piece. Their detection is a long and laborious activity, difficult to implement with traditional techniques since the volumes are not defined by regular surfaces. The geometrization, usually applied in the graphic representation, is often the result of inadequate simplifications of structures characterized by complex geometries and shapes, often dictated by the need to speed up the work. The same representation, operated by the usual methods, poses considerable difficulties in the graphic transcription of metric and formal data and is generally unsatisfactory in conveying the complexity of the internal spatialities. Knowing in-depth and representing explicitly and with appropriate levels of precision, a rocky and rough space like a cave require a careful spirit of observation, critical sense and graphic skills. It can certainly benefit from a sage use of the advanced 3D laser scanning and image-based 3D reconstruction methodologies. 

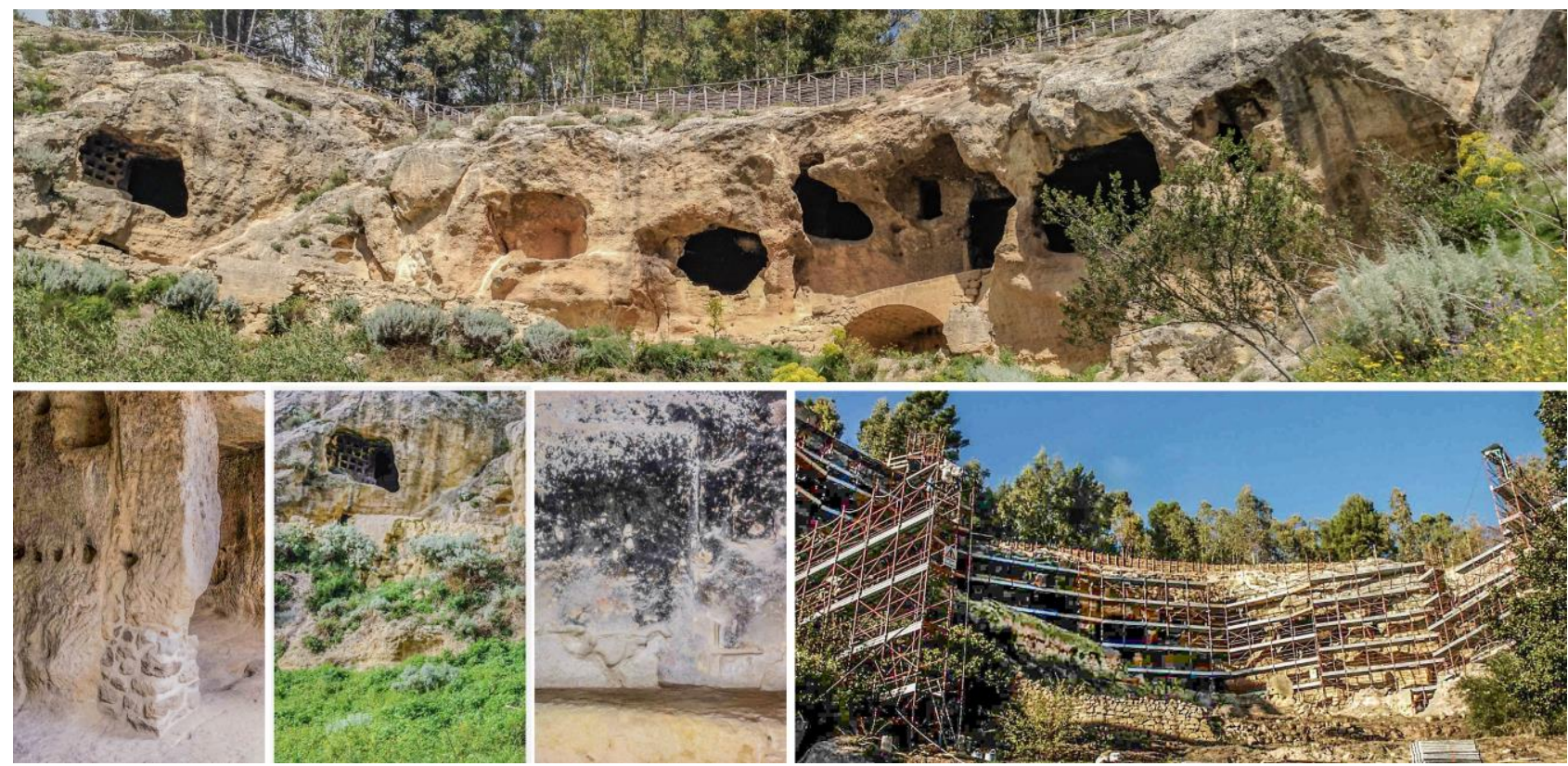

Figure 2. The Canalotto Valley: today and during the consolidation works undertaken in 2000.

The survey of the village of the Canalotto valley has therefore been carried out by the integration of the most innovative geomatics techniques. Rapid and sparse 3D laser scanning was performed on the entire site, both on the top of the hill and at the base of the risers to geo-refer the models within a unique system, marked by topographic cornerstones. The model obtained - the so-called point cloud - is a vast digital archive that allows unquestionable ease in processing orthographic projections of complex surfaces. Besides, the irregularities measured by modern electronic sensors is not a marginal element but an extremely useful peculiarity for the interpretation of the marks, which can be observed on the surfaces. In particular those due to the techniques and tools of excavation used, which are essential clues for understanding the stages of development and growth of the entire hypogeum.

The measurements, if carried out over time repetitively and regularly, can help to evaluate the degradation of the surfaces and determine their growth curve. The comparison of scans carried out several years apart can guarantee an understanding of the evolution of the rock erosion - when greater than $5 \mathrm{~mm}$ - due to meteoric events, highlighting the areas where the phenomenon is more intense and worrying. The product from the scan made with active sensors is, in any case, a raw data which, if properly treated, however, describes the object through a discontinuous model in which the perception of the 'real' object is higher the denser is the cloud, but lacking the radiometric information. Hence the need to build a photogrammetric model to correctly map the built, its materials and state of conservation.

The acquisition and digitization of 3D data have been the first phase of an information processing process followed by 3D modelling for the creation of textured and navigable virtual artefacts. Models capable of providing a realistic description of the site, with accurate metric information (Ebolese et al., 2019).

The next phase, the so-called 3D modelling, began with the transformation of the point cloud into a discrete - or continuous - surface through the generation of meshes, fragmented surfaces made up of triangular polygons whose vertices were the points constituting the cloud. The model obtained, a polygonal solid, was subjected to cleaning procedures to erase extraneous and inconsistent data. Consequently, it underwent a refinement through the recording process (made by an ICP shape control algorithm that aligns each range scan according to the shape of its surfaces and not based on the targets only) and, lastly, the decimation and the union of the meshes in a single object.

The polygonal model was then subjected to a final editing phase to correct the errors generated in the casting process, to close the gaps and discontinuities. It has then been optimized with the reduction of the total number of triangles to a predetermined value and the mapping of the material textures for the final rendering. New software, such as Zephyr ß3DFlow, can manage in a single virtual environment, both photogrammetric and 3D laser scanning models, allowing the integration of data and their fusion.

Therefore, the accuracy of the model acquired with active sensors becomes the geometric support on which to 'rely on' and adapt the photogrammetric model with its wealth of chromatic information (Figure 4).

\section{PREVIOUS CONSOLIDATION WORK}

As already mentioned, the Byzantine village of Vallone Canalotto constitutes a uniqueness that gives value to the territory. On the one hand, for how this place was shaped through the excavation of caves and tunnels. On the other hand, because of the long time during which the rock site was frequented, from the second millennium BC to the 1900s (Amata, 2016).

The communities that successively inhabited it have placed a particular preference for the organic characteristics with which the village merges with the valley and the Morello River. Here, every sign found - from the houses to the necropolises, from the places of production to the same water pipeline of the qanāt carved out of the rock - is the emblem of the concept of landscape, intended as an inseparable unicum between human activities and natural phenomena.

Vallone Canalotto in its current dual condition of a partially accessible archaeological site and naturalistic park plays an important historical role. Its conservation is, however, at risk. 
The slopes of the Morello river valley are characterized by a very soft sandstone rock. Primarily carved by the same river course, it was later very easily excavated by the inhabitants, allowing their settlement.

However, precisely the friable nature of these rocks, if it has facilitated their workability over the centuries, today makes the site vulnerable. Caused by wind power and the runoff of rainwater, the erosive and disruptive phenomena are widespread and could compromise the site conservation and its same future.

In 2000, on the initiative of the Enna Regional Province in collaboration with the Superintendency BB.CC.AA. of Enna and the Municipalities of Calascibetta and Villarosa, various interventions were undertaken. They aimed at enhancing and using the archaeological sites belonging to the Morello Valley, in particular, the area of Vallone Canalotto in Calascibetta and those of Casa Bastione, Contrada Gaspa and Monte Giulfo in the territory of Villarosa.

The project carried out at the Xibetan site also provided for a series of conservation activities aimed at stopping or, at least, limiting the degradation processes of a physical-chemical and biological nature that significantly threaten the archaeological remains. The interventions primarily concerned the restoration and consolidation of the hypogea in more critical conditions. The aim was to preserve the peculiarities of the rock architecture, obviously taking into account their geomorphological and structural characteristics.

It is easy to understand how in a place so fragile and until recently, totally abandoned to itself, the degradation phenomena could be numerous. However, as a first phase - which allowed in the past years, to be able to visit and get to know the places being studied - the intervention was aimed at combating two macroscategories of decay that seemed in need of priority interventions.

The first was linked to cracks in the rock matrix, of tectonic origin, very often worsened by anthropic action. These phenomena have undergone a further aggravation, since they have evolved and continued, triggering processes of a physicalchemical nature of saline dissolution and biotic agents. The root systems of the present vegetation determined internal thrusts to the rock, causing significant damage to the structures and thus making them unstable and unsafe for use. The second, on the other hand, was due to the processes of wind erosion that affected the rocky walls composing the architectural structures, causing their disintegration and decreasing their mechanical strength, however, affected by the action of some animal species that, by their nature, dig dens and shelters in the rock.

Other pathologies, albeit minor, have been identified within all environments of the rock village. In the years preceding the site enhancement and conservation, the Byzantine village sites were at the mercy of everyone, especially shepherds, who used these places as a grazing area and the hypogea accessible from the walkway, as a stable and place of animal shelters, as evidenced by the numerous signs engraved in the rock. Furthermore, until the first thirty years of the 20th century, the grottos were used as a dwelling. For this reason, extensive areas heavily affected by the so-called 'black smoke', caused by the continuous presence of domestic outbreaks, have been found on the ceilings and walls of rooms used in the past as kitchens. Secondary decay phenomena were found where the minor vegetation had in some way invaded the rocky surfaces and the paths created to ensure the use of the different places of interest in the village.

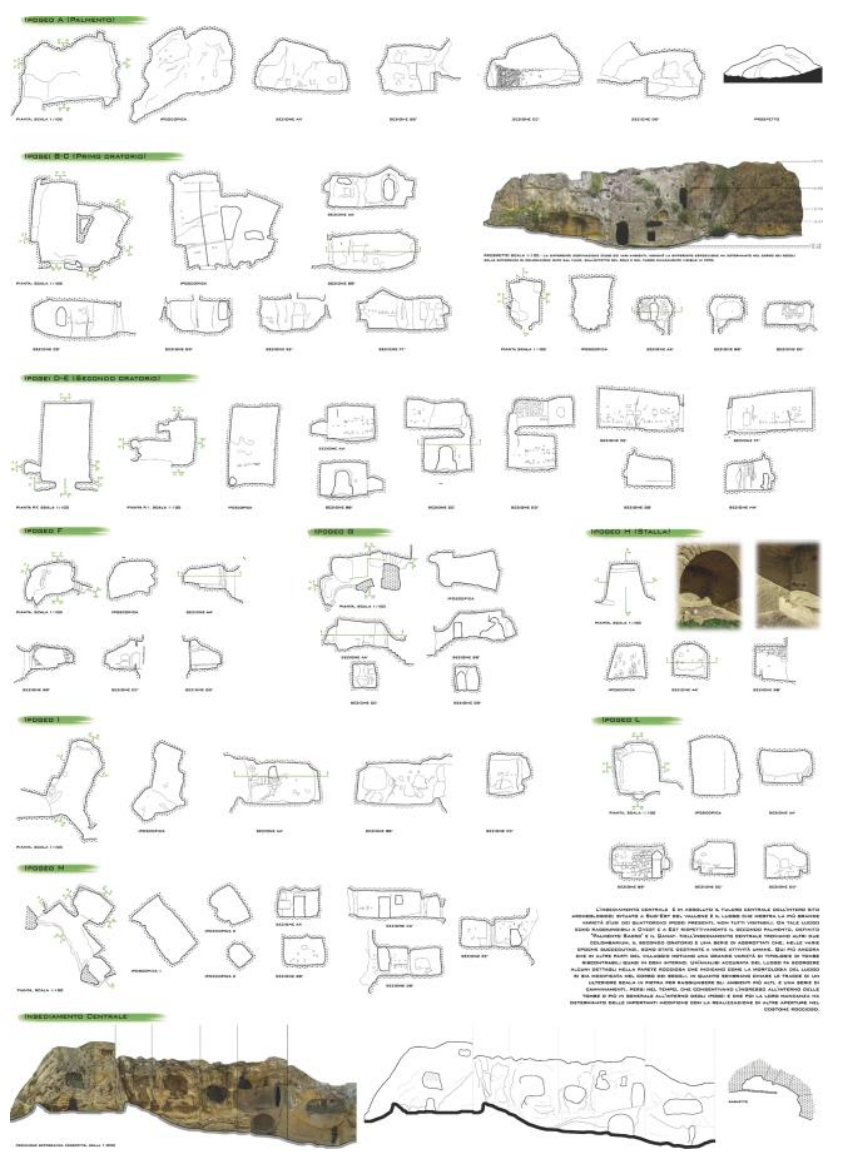

Figure 3. Survey and typological analyses of rock-cut spaces.

Regarding the first macro-category, the interventions carried out have taken steps to limit the infiltrations, by sealing the cracks, in an undercut of $2 \mathrm{~cm}$, preceded by cleaning from the earth deposits, with the aid of a hydraulic mortar based on hydraulic and pozzolanic binders. Then, cortical consolidating products were prepared, which met the primary need to block the erosive action of the wind, creating an invisible protective patina.

For the second category, only when necessary, to avoid aggressive alterations of the architectural artefacts, the creation of barriers to stop the phenomenon of wind erosion by filling the voids, was planned. The aim was to shield the action of the wind with stone walls, of a limestone nature similar to the rock of which the hypogea are made, and hydraulic binders. However, this type of intervention was limited when strictly necessary, as considered too invasive and evident.

At the beginning of the works, the rocky ridge of the main settlement had serious instability and stability phenomena. To prevent the triggering of slumping phenomena or kinematic mechanisms due to the sliding of multifaceted blocks between the discontinuities sub-parallel to the rocky walls, it was decided to intervene with an imposing consolidation.

The intervention provided for the construction of anchor rods to contain and stop the flaking of the rock walls, from which rock layers were lost, even of considerable dimensions during the implementation phases. The project also provided for the installation of steel stranded rockfall nets with hinged uprights that would prevent the rolling of the stones on the ground below, the relative anchoring nails and all the other structural interventions necessary to allow safe access in the frowns. However, this intervention has never been realized. 

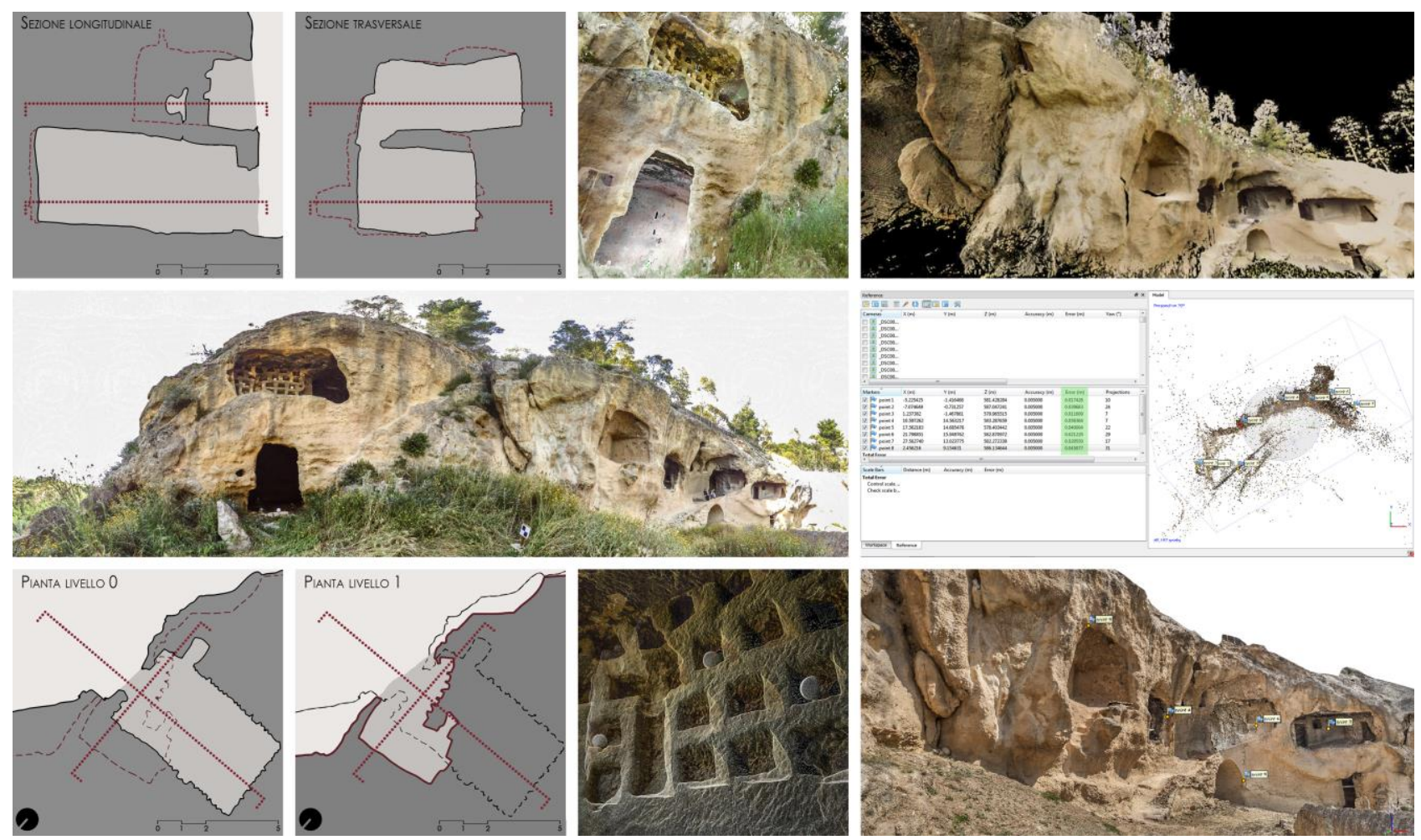

Figure 4. 3D laser scanning and Image-based 3D Reconstruction.

The preliminary scaling of both all those boulders and portions of the rock face that were close to the fall was also carried out, in correspondence with the areas frequented by users.

To realize these interventions, specialized personnel were recruited who operated by the local breaking of the falling blocks, the use of mechanical or chemical expansive means, following the safe harnessing of the blocks with net and ropes, to limit as much as possible further damage or danger to the different areas of the valley.

With particular reference to the central settlement of the valley, even before the consolidation interventions, cleaning operations were also necessary from the thick vegetation that did not allow a complete and exhaustive vision and analysis. In fact, following the removal of the vegetation, very illegible elements were highlighted, such as the access road to the site that skirted the western side of the rocky cliff and a system of steps that allowed getting around the points more impervious along the path that led to the central settlement.

The vegetation cleaning also concerned other areas of the village, such as the first millstone, characterized by the presence of a wall made up of stone blocks completely covered by weed, the access road to the first oratory, the second millstone with a relative access road. It also concerned two columbaria, above the millstone, which over the centuries had been affected by landslides and therefore made inaccessible and invisible from the outside. Despite the works carried out, in not too remote times, the stability and survival of the Byzantine Village are still precarious, affected by old and new problematics.

\section{SLOWING DOWN AND MONITORING THE DEGRADATION PHENOMENA: CONSERVATION CRITICALITIES AND INTERVENTION ASSUMPTIONS}

The new study here exposed has been conducted in the rock village from 2014 to 2019 . It has allowed monitoring the degradation phenomena - erosion especially -, both in terms of their extent and intensity. The knowledge acquired throughout of the five-years investigation has supported the intervention hypotheses. This, in the awareness that the higher the knowledge of the current state and its causes, the greater the chances of succeeding in that work of slowing down the alteration processes that we call 'conservation' (Laurenzi Tabasso, 1987).

The local association Hisn Al Giran as tried to ensure the maintenance of the place since 2000. Thanks to the competence and professionalism of figures specialized in the field of archaeology, it periodically carries out - in a laudable way numerous initiatives. Despite the limited funds available, it organizes tours and excursions, which feed routine and periodic maintenance activities. However, not all this is enough to deal with increasingly critical issues that would require much more expensive interventions and the interest of municipal, provincial and regional bodies.

One of the critical issues only marginally faced by the interventions carried out in 2000, concerns the treatment of the internal surfaces covered by a black-smoke patina; this phenomenon, inside the village, is still present in the vast majority of the grottos, with particular reference to the hypogea of the central settlement. It is the formation of incrustations, near the walls and ceilings, of black colour, precisely, caused over the centuries by the various human activities. 
However, this patina has been further accentuated in much more recent times, when precisely, as already mentioned, these areas, without fencing until recently, were easily accessible to local shepherds. The latter - regardless of the great damage that they could cause to the structures and above all indifferent to the low resistance of the rocky wall - have used these covered environments, as stables, but also, unfortunately, as places, within which, carry on their dairy production. The lighting of fires, inside has, therefore, determined and sometimes further aggravated the formation of these black pigmented layers, which cover large portions of the hypogean surface.

Based on the above, three different cases have been identified: the caves restored in 2000 in which the black smoke patina had been removed, the environments in which the deposited patina was rather recent and datable at the end of the 20th century and, finally, the environments in which the black smoke was evidence of their much older use. Accordingly, treatment proposals on the internal surfaces were developed.

In the first case, the cleaning actions performed in 2000 removed the cortical layer for a thickness ranging from a few millimetres to $2-3 \mathrm{~cm}$. This involved the elimination of important traces, in particular the signs of the excavation tools, but at the same time, also exposed the surfaces to ageing. The compactness of the black smoke layer also carried out a consolidating and protective action. The consolidating products used in the intervention - assuming their correct implementation - do not appear effective today. It is sufficient to touch the surfaces treated in this way to test their extended friability. A situation that requires new surface consolidation actions.

Concerning the recent black smoke patina, it is planned to intervene preliminarily through the removal of incoherent and powdery deposits, using techniques that respect the perishable nature of the material. This is possible thanks to the use of cannulas connected to low-pressure aspirators, soft brushes and final dusting with low pressure compressed air jets, which go to act where necessary for the removal of the most superficial and inconsistent black layers smoke, preparing the lithic material for subsequent consolidation. A consolidation of the surfaces is expected with products based on ethyl esters of silicic acid (Mameli, 2012) particularly suitable for the porosity and wettability of the sandstone present on the site. The effectiveness of this treatment can be guaranteed by an installation through the impregnation at a considerable depth of the product. This is obtainable by prolonged percolation or repeated tampons with a brush. On the other hand, the spray application, even if prolonged for many hours, produces a penetration of a few millimetres, with a return of the degradation processes in a few years (Rossi Manaresi, 1987).

For the third case - i.e. when there are traces of black smoke dating back to more ancient times -, preliminary treatment to remove only superficially deposited dust and the impregnation of the consolidating surfaces are envisaged, as in the previous case. Another particularly widespread degradation phenomenon is given by a plant - the mugwort - belonging to the Asteraceae family. Its presence affects large portions of the central settlement, where over the years it has undergone a process of massive expansion, causing significant damage to the stability of the rocky cliffs. In past years, an attempt has been made to remove the weed species and the subsequent sealing of cracks that, the roots of this and other plant species, had caused on the rocky ridge, due to the thrusts determined by them. After an initial weeding operation, however, it is still possible to note how the mugwort continues to spread like wildfire, causing further damage.
When observing the central settlement from above, what immediately catches the eye is the presence of a stonewall, located in the lower part of the settlement, used in the past to delimitate the place and which, during the first findings made in 2014, was almost completely intact. A few years later, due to the shoves and pressures exerted by the artemisia roots, the wall has halved its extension. The collapses and landslides of the rocky parts of the latter have strongly affected the stability of the wall as well as its geometric and functional integrity.

As previously mentioned further problems concern the phenomena of erosion and generalized disintegration. The enhancement, restoration and protection project carried out in the year 2000 already had among the objectives and purposes to be achieved, that of limiting or stopping the erosion process due to the action of atmospheric agents and in particular to wind power.

Unfortunately, as mentioned, the caves' stone is extremely tender, so, despite past interventions, the process continues to make headway, especially in those hypogea, or in parts of them that are most exposed to the external environment. Erosion is now visible and observable everywhere in the valley (Figure 5 ); this means, that as in the past, the evolution of this phenomenon will lead to the loss of further traces and physical evidence of past generations. For this reason, continuous protection and conservation actions are necessary, carried out according to a coherent and adequate schedule, to allow adequate maintenance of the structures and archaeological values.

In this perspective, the presence of subjects - such as the Hisn Al Giran cultural association - is essential. Bodies in charge of the protection, who would devote themselves to routine and periodical maintenance work and to surveillance. Activities aimed at informing the managing authorities about the occurrence of conservation problems before the consequences become irreversible, thus actively acting through prevention.

\section{ACCESSIBILITY AND USE OF THE SITE AS A RESPONSE TO THE DANGERS OF ABANDONMENT}

Following analysis and on-site inspections, the main criticalities which were found found are related to three macrocategories: the first dealing with physical issues concerning the integrity of the structures and their environement, the second related to the correct use of the site and finally the third related to safety and security of visitors.

To make a site like that of the rock village of Vallone Canalotto accessible to a wide range of people is a complex issue. If on the one hand, the process aims to increase the attendance of this place, avoiding its abandonment, on the other hand, it must respond to the needs of a sustainable future transmission of the testimonial value of which this place is a harbinger. "It is, therefore, necessary to find a fair compromise between the contemporary needs of accessibility and use, which in themselves generally represent the first step to guarantee the conservation of an asset, and the cultural ones of conservation and safeguard, aimed at guaranteeing the survival of the spatial and material characteristics of the preexisting structures and of their historical-aesthetic values" (Bartolomucci, Giannattasio 2009, p. 52). Although, to date, little known and valued, this place offers various possibilities for architectural, archaeological and landscape enjoyment. 

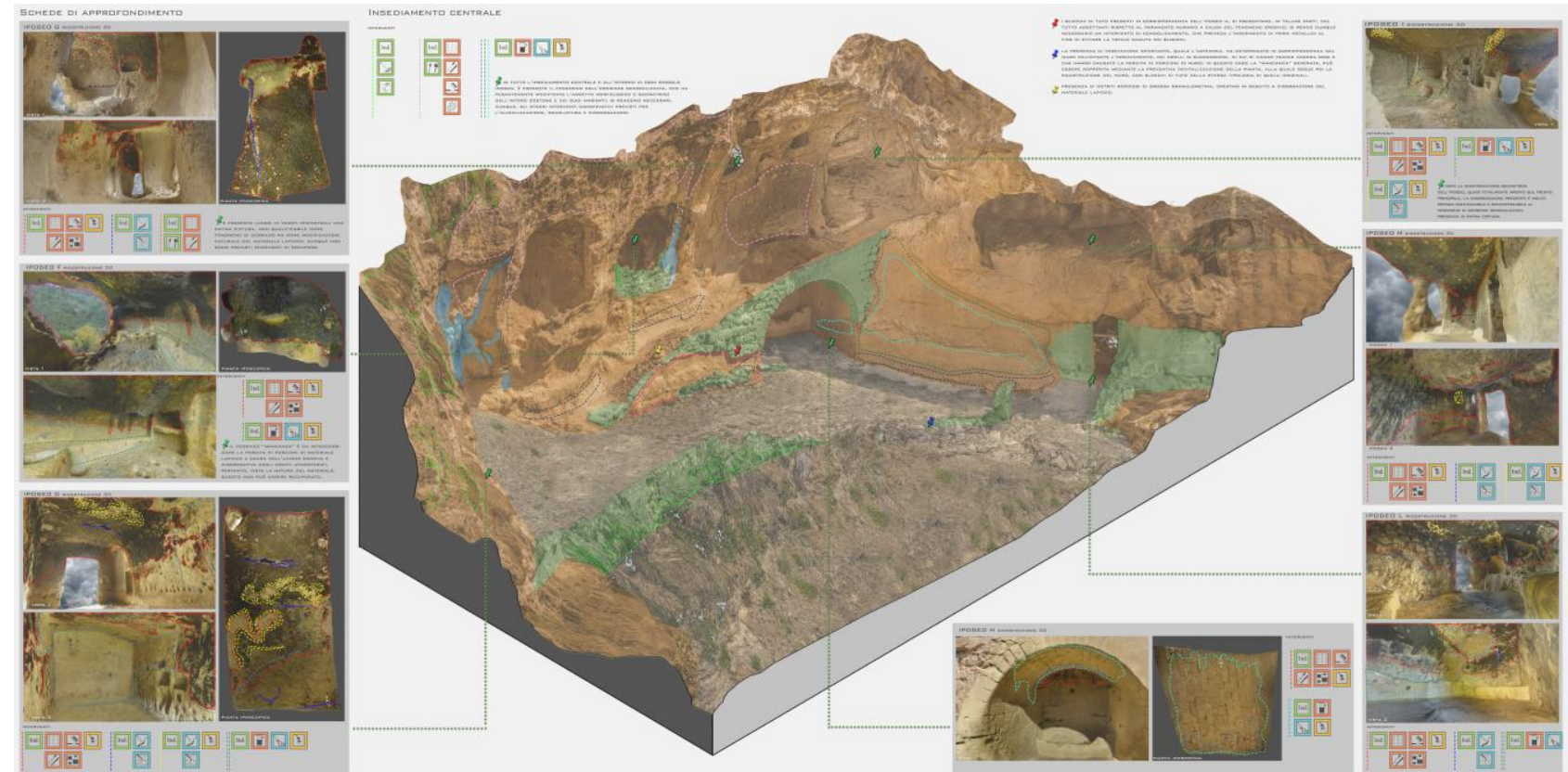

Figure 5. Decay mapping of the surfaces on a 3D model. The wide extension of erosion and other disruptive phenomena is very evident.

On these assumptions, careful design planning was, therefore, established. The proposal would allow, according to the needs and nature of the site, the overall reading of the existing resources, in view of the creation of an archaeological park, through a constant integration between protection, management and research. Starting from an accurate survey - performed with specific methodological rigour and advanced digital software it was possible to obtain a 3D model of the rock environments, which constituted precise and detailed support for the decay mapping. Each degradation phenomena previously illustrated was then three-dimensionally represented in its precise spatial reference; its dimensions and extensions were then geometrically localized.

The model also proved to be particularly useful for the design of some additions allowing the enhancement and increase of site accessibility. "Taking action by adding a new layer represents the correct path also in the field of heritage protection. This applies even more in the very specific context of accessibility, where the insertion of devices for overcoming architectural barriers, almost always inherent in the identity of the building or historic site, is the only possible way to improve the accessibility of places often born without any attention to these needs" (Arenghi, Pane, 2016, p. 57).

The project so involved the improvement of the use of the site. To allow an easy and safe stay of visitors, new services and functional elements have been designed. New paths (sometimes, thematic ones) adequately equipped with lighting elements, protection parapets and rest areas were studied. Elements for educational purposes such as interactive workstations and interactive display cases distributed inside the caves have been conceived.

The program intends to meet the needs of all types of users including disabled ones - at the service of which a new and more functional structure, located at the entrance of the site and hosting an info point, a bookshop and a cafeteria, has been foreseen (Figure 6).

\section{CONCLUSIONS}

This research has intended to highlight how the application of a working methodology based on the integration of different geomatics techniques and the adoption of a common reference system can be very helpful especially for archaeological assets, characterised by complex shapes and articulated surfaces. This case study has shown how the parametric model can be a valid support for the effective representation of decay mapping and its interpretation.

Such a procedure, based on well-planned survey acquisitions, the consequent generation of interoperable parametric objects, the association of semantic information on the built assets, can be usefully used for the conservation, restoration and monitoring activities. Accordingly, the proposals envisaged for the Byzantine Village in Vallone Canalotto were aimed to encourage architectural, archaeological and landscape improvement, as well as to promote the tourist vocation of the area, consistently with the principles of minimal intervention and environmental impact and following high-quality standards.

Here the archaeological research and the architectural and landscape design need to coexist organically, integrating each other for the achievement of concrete and significant objectives.

\section{ACKNOWLEDGEMENTS}

The figures of this paper are taken from the Master Thesis in Architecture of Alexa Lo Cascio, Per una conservazione integrata dell'archeologia e del paesaggio. Nuovi percorsi di conoscenza e fruizione del sito rupestre di Vallone Canalotto a Calascibetta (En), University of Enna 'Kore', academic year 2017-2018 (Supervisor: prof. A.Versaci - Advisor: arch. L. R. Fauzìa). 


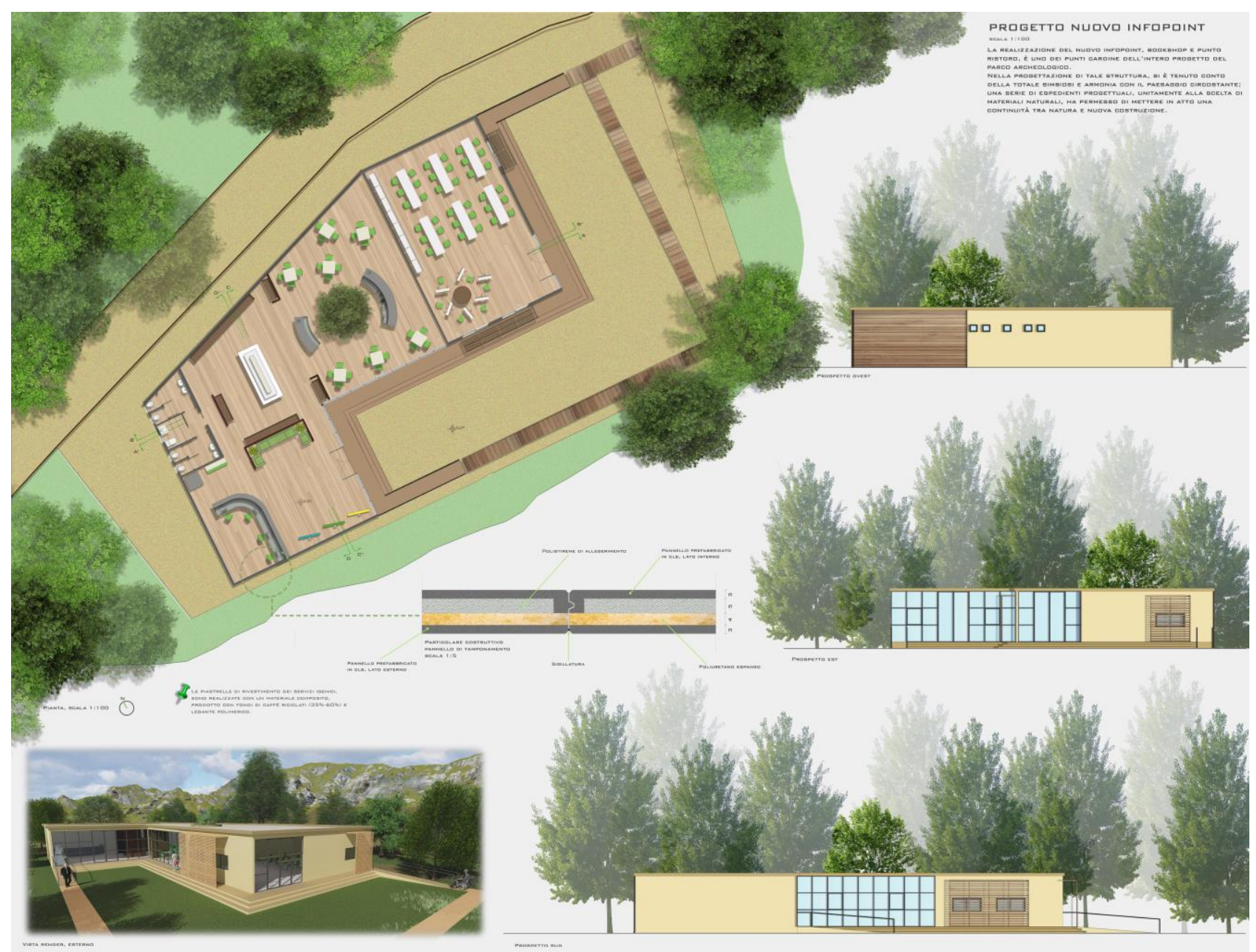

Figure 6. Design of structures with reduced visual impact aimed at hosting services for the public.

\section{REFERENCES}

Amata, S., 2016. Valle del Morello. Un microcosmo al centro della Sicilia. Archeologia Viva, XXXV(180), 28-39.

Arenghi, A., Pane, A., 2016. L'aggiunta nel progetto di restauro per l'accessibilità del patrimonio culturale. TECHNE, 12,57-64.

Bartolomucci, C., Giannattasio, C., 2009. Il conflitto tra accessibilità e fruizione nel progetto di conservazione. Recupero \& Conservazione, 89, 38-49.

Cardaci, A., Versaci, A., Fauzia, L.R., 2015. 3D documentation for archaeological conservation: some case studies in Central Sicily. SCIRES-IT, 5(2), 49-70.

Cigola, M. 2001. Il rilievo per la conoscenza del costruito, in Gallozzi, A, Longo, M.T, Paris, L. and Cigola, M. (eds), Metodi e tecniche della rappresentazione. Cassino: Uni Press, 15-38.

Dezzi Dardeshi, M. (ed), 2017. Abbeceddario minimo 'Ananke': cento voci per il restauro (Italiano). Firenze: Altralinea.
Ebolese, D., Lo Brutto, M., Dardanelli, G., 2019. The integrated 3D survey for underground archaeological environment. ISPRS International Archives Photogrammetry and Remote Sensing. Spatial Inf. Sci., XLII-2/W9, 311-317.

Laurenzi Tabasso, M., 1987. La Conservazione dei materiali lapidei; aspetti scientifici e tecnici, in Bureca, A., Laurenzi Tabasso, M., G. Palandri G. (eds), Bollettino d'Arte. Materiali Lapidei Problemi relativi allo studio del degrado e della Conservazione, 41, 133-143. Roma: Ministero per i Beni Culturali e Ambientali.

Masini, N., 2004. Metodologie di rilievo e di analisi della cultura costruttiva dell'architettura ipogea, in Menesto, E. (ed), Quando abitavamo in grotta, Spoleto: Centro Italiano di Studi sull'Alto Medioevo, 97-121.

Rossi Manaresi, R., 1987. Pietre porose: alterazione e conservazione, in Bureca, A., Laurenzi Tabasso, M., Palandri, G. (eds.), Bollettino d'Arte. Materiali Lapidei Problemi relativi allo studio del degrado e della Conservazione, 41, 133-143. Roma: Ministero per i Beni Culturali e Ambientali. 